\title{
Strengths Based Coaching-A Positive Psychology Intervention
}

\author{
Jolanta Burke and Jonathan Passmore
}

\begin{abstract}
Strengths approaches have grow in popularity over the past decade, with a profileration of writing, models and questionnaires used for strengths assessment and in coaching. These questionnaires include including VIA, Strengthscope and StrengthsFinder and Strengths Profile. The questionnaires have become a popular intervention for consultants, HR professionals and executive coaches for adding both personal development and coaching, to assisting with recruitment and selection. We will briefly review in the first section of this chapter three popular questionnaires, considering their development and constructs. In the second section we will explore positive psychology coaching as an intervention using questionnaires and strengths cards, before reviewing the research evidence and opportunities for future research.
\end{abstract}

Keywords Strengths coaching $\cdot$ VIA $\cdot$ StrengthsFinder $\cdot$ Strengthscope $\cdot$ Strengths cards

\section{Introduction}

For over a century both researchers and practitioners have been interested in talents as the nature of work has changed (Drake, 1935; Subarsky, 1948). This has seen the emergence of the 'war for talent' (Michaels, Handfield-Jones, \& Alexrod, 2001), with corporations competing to recruit or retain what they perceive to be the most able employees. While the crash of 2009 saw a decline in this recruitment, the topic has re-emerged, with firms continuing to seek to attract the most able through their recruitment strategies. While talent is considered, in psychological terms, to be a natural or innate ability to achieve an outcome faster or to a higher standard (Duckworth, Eichstaedt, \& Ungar, 2015), for these firms, it is considered to be 'the bright

\author{
J. Burke ( $ه)$ \\ University of East London, London, UK \\ e-mail: jonathancpassmore@yahoo.co.uk \\ J. Passmore \\ Henley Business School, University of Reading, Henley on Thames, UK \\ (C) Springer Nature Switzerland AG 2019 \\ L. E. Van Zyl and S. Rothmann Sr. (eds.), Theoretical Approaches \\ to Multi-Cultural Positive Psychological Interventions, \\ https://doi.org/10.1007/978-3-030-20583-6_21
}

463 
and best from the top universities'. The psychological definition remains relevant, but the term continues to be overused in common parlance, leading to misunderstandings and confusion (Tansley, 2011). Of course examples like Enron (McLean, 2004) confirms that despite being the smartest guys, corporate failure can still follow, and factors like employee-role fit, motivation and experience remain factors to be considered in successful recruitment strategies', alongside innate ability (Goldstein, Pulakos, Passmore, \& Semedo, 2017).

Alongside these discussions of talent, there has been significant interest in what might be considered to be the dark side of talent (Lombardo \& Eichinger, 1999; Furnham, 2015). These writers and others like Robert Hogan (Hogan, 2007) have drawn attention to attributes, traits or talents, which can contribute to failure or derailment. One example is the development of a fixed mindset. For talented individual this can occur due to early successes in formal education or career, leading to less willingness to learn and adapt to changing role and competitive environmental demands (Dweck, 2009; Duckworth, 2016; Furnham, 2015). But the multiple examples exist across the behavioural spectrum.

One of the first attempts of combining talent with individuals' further development came from the Gallup StrengthsFinder (Clifton \& Anderson, 2001-02). According to the Gallop model, while talents could be wasted (not developed), their development, through the acquisition of knowledge and skills, talents can become a higher-order talents; a 'strength'. This concept of strength recognises the importance of both innate attributes with development.

In this chapter we explore; strengths based coaching. We will start by reviewing the development of different conceptual approaches to strengths that have been developed into three widely used questionnaires in strengths. We will briefly explore the development of these tools, and the themes which they include. In the second section we will explore positive psychology coaching and its use of strengths based questionnaires. In the third section will consider the research evidence and whether strengths coaching is an effective approach to use with clients. Finally, in this short chapter on interventions, we will review opportunities for future research.

\section{Different Approaches to Strengths}

Over the past two decades we have seen the emergence of a number of alternative approaches to strengths, such as Values into Action (VIA), StrengthsFinder and Strengthscope and their operationalization as tools for use in organisational or wellbeing coaching. In Table 1 we consider the development of these approaches. We will review three popular models that have been published in English.

StrengthsFinder is based on the theory that each adult possesses a number of personal character attributes, known as 'Talent themes' (Asplund, et al. 2014). Through awareness of these talent themes and focused practice, strengths can be created and effectiveness enhanced. The model consists of 34 strengths, such as strategic, learner, achiever, self-assurance, and woo (Gallup, 2018). These are sorted into four 
Table 1 StrengthsFinder questionnaire's 34 strengths

Achiever - one with a constant drive for accomplishing tasks

Activator - one who acts to start things in motion

Adaptability—one who is especially adept at accommodating to changes in direction/plan

Analytical —one who requires data and/or proof to make sense of their circumstances Arranger-one who enjoys orchestrating many tasks and variables to a successful outcome

Belief - one who strives to find some ultimate meaning behind everything they do

Command-one who steps up to positions of leadership without fear of confrontation

Communication - one who uses words to inspire action and education

Competition-one who thrives on comparison and competition to be successful

Connectedness - one who seeks to unite others through commonality

Consistency-one who believes in treating everyone the same to avoid unfair advantage Context - one who is able to use the past to make better decisions in the present

Deliberative - one who proceeds with caution, seeking to always have a plan and know all of the details

Developer-one who sees the untapped potential in others

Discipline - one who seeks to make sense of the world by imposition of order

Empathy-one who is especially in tune with the emotions of others

Focus - one who requires a clear sense of direction to be successful
Futuristic - one who has a keen sense of using an eye towards the future to drive today's success

Harmony — one who seeks to avoid conflict and achieve success through consensus Ideation-one who is adept at seeing underlying concepts that unite disparate ideas Includer - one who instinctively works to include everyone

Individualization - one who draws upon the uniqueness of individuals to create successful teams

Input - one who is constantly collecting information or objects for future use Intellection-one who enjoys thinking and thought-provoking conversation often for its own sake, and also can data compress complex concepts into simplified models Learner-one who must constantly be challenged and learning new things to feel successful

Maximizer-one who seeks to take people and projects from great to excellent

Positivity —one who has a knack for bringing the light-side to any situation

Relator-one who is most comfortable with fewer, deeper relationships

Responsibility —one who must follow through on commitments

Restorative — one who thrives on solving difficult problems

Self-Assurance - one who stays true to their beliefs, judgments and is confident of his/her ability

Significance - one who seeks to be seen as significant by others

Strategic - one who is able to see a clear direction through the complexity of a situation Woo- one who is able to easily persuade (short for "Winning Others Over")

business-competency-related domains of strategic thinking, executing, influencing, and relationship building.

Even though the concept of strengths is not new (e.g. Weick \& Saleebey, 1995), StrengthsFinder was the first assessment tool, which helped individuals identify their strengths and create a language around them. As a commercial tool, it has been used extensively (Gallup, 2008), however a literature review by the authors (completed in 2018 for this chapter) reveals little peer review published material about the instrument, its development and its validity as a developmental tool. 
Table 2 VIA strengths VIA-IS (2018)

\begin{tabular}{|c|c|}
\hline Wisdom and knowledge & $\begin{array}{l}\text { Creativity } \\
\text { Curiosity } \\
\text { Judgment } \\
\text { Love of learning } \\
\text { Perspective }\end{array}$ \\
\hline Courage & $\begin{array}{l}\text { Bravery } \\
\text { Perseverance } \\
\text { Honesty } \\
\text { Zest }\end{array}$ \\
\hline Humanity & $\begin{array}{l}\text { Love } \\
\text { Kindness } \\
\text { Social Intelligence }\end{array}$ \\
\hline Justice & $\begin{array}{l}\text { Teamwork } \\
\text { Fairness } \\
\text { Leadership }\end{array}$ \\
\hline Temperance & $\begin{array}{l}\text { Forgiveness } \\
\text { Humility } \\
\text { Prudence } \\
\text { Self regulation }\end{array}$ \\
\hline Transcendence & $\begin{array}{l}\text { Appreciation of beauty } \\
\text { Gratitude } \\
\text { Hope } \\
\text { Humour } \\
\text { Spirituality }\end{array}$ \\
\hline
\end{tabular}

The second, popular strengths assessment is the Strengthsscope (Brook \& Brewerton, 2006). Its strengths are divided into four categories; emotional, relational, execution and thinking strengths, with 24 strengths. In addition to creating a strengths' assessment, Strengthscope has also introduced the concept of strength-overuse (Brook, 2008), which has since been adapted by other strengths assessments. It refers to individuals overusing their strengths, which may result in their strengths becoming weaknesses. Of all the three tools, the StrengthScope is the only measure to have achieved the registered test status by the British Psychological Society (BPS, 2017).

The third questionnaire which we will briefly review has had wide exposure; VIA-IS (Peterson, Park, \& Seligman, 2005), offering greater transparency in its conception, development and research (McGrath, 2014; McGrath, 2017a; Peterson \& Seligman, 2004).

VIA consists of 24 character strengths, divided into 6 virtues, wisdom, courage, humanity, justice, temperance and transcendence. The questionnaire aims to measure the frequency of use of the 24 strengths, with those most frequently used labelled as 'signature strengths' (Table 2).

Various studies have showed the benefits of using the VIA's signature strengths on a regular basis, ranging from enhancement of well-being (Mongrain \& AnselmoMatthews, 2012), through to flourishing (Hone, Jarden, Schofield, \& Duncan, 2014), 
happiness (Proyer, Wellenzohn, Gander, \& Ruch, 2014), satisfaction with life and reduction in anxiety (Peterson \& Peterson, 2008). However, there is also evidence of the benefits of using and developing weaknesses that show positive outcomes (Rust, Diessner, \& Reade, 2009). Therefore, what the research on character strengths claims is that as long as individuals develop their trait-like qualities, they are likely to see a range of benefits in their personal and professional lives.

The 24 VIA character strengths are not exhaustive, or exclusive. The developers of the model (Peterson \& Seligman, 2004) recognise the model may need to change, along with changes to the questionnaire used to identify signature strengths (Peterson \& Seligman, 2004). McGrath (2017b) carried out significant work on reviewing the psychometric properties of the original questionnaire, and in the light of the research carried out in the first decade after its creation. This research confirmed the high validity of the questionnaire, but included recommendations about use, noting that higher levels of validity were achieved from the longer form questionnaire and noting the challenges of using the questionnaire with individuals with cognitive impairments.

This work has lead to improvements to the questionnaires (McGrath, 2017b). They also indicate signature strengths, overuse, underuse and optimal-use of character strengths that identifies whether or not strength-use is balanced (Freidlin, LittmanOvadia, \& Niemiec, 2017), which can serve as a starting point for coaching discussions. Furthermore, they are available for $360^{\circ}$ assessments, whereby partners can identify individual's perceived strengths (Kashdan et al., 2018), which can be compared to the self-assessed character strengths. Also, the new assessment can identify weaknesses and measures of virtues, not only strengths (McGrath, 2017b). Therefore, the measurement tools created extend to a comprehensive assessment of strengths.

Alongside these validated instruments, a host of consultants and practitioners are now publishing 'Strengths cards'. These cards typically consist of 40-80 playing cards with images, which aim to facilitate a discussion about the image and lead to an exploration of the client's strengths. However, our literature review found no peer review published research regarding the value, or the reliability or validity of strengths cards as a coaching tools.

We have briefly explored four different strengths frameworks which have been operationalized into questionnaires, as well as briefing discussing strengths cards. As a result we define strengths as "an attribute, either innate or learned, which when used by the individual leads to superior performance".

As we discuss in the next section, both the questionnaires and strengths cards are being increasing used in coaching work with clients. In the next section we will explore how they are being used and their contribution to outcomes.

\section{Strength-Based Coaching Practice}

With the growth of positive psychology coaching (Freire, 2013) coaching practitioners have been drawing on both positive psychological models to apply in their 
coaching practice (Passmore \& Oades, 2014a; 2015a; 2015b, 2016), as well as looking to strengths models to use with their clients (Kaufman, Silberman, \& Sharpley, 2012: MacKie, 2015). Biswas-Diener and Dean (2007) began a discussion about positive psychology coaching pointing out the similarities between the fields of positive psychology and coaching psychology and encouraging using strengths assessments and their outcomes in a coaching practice. Biswas-Diener approach has been further advanced through a practical guide to applying positive psychology coaching with clients (Biswas-Diener, 2010). Following from this, strength-use has been proposed by Passmore and Oades (2014b), as a fundamental part of positive psychology coaching. More recently, Burke (2018) argued in the conceptual framework for a positive psychology coaching practice that using strengths questionnaires in coaching are an essential element of positive psychology coaching.

We suggest strengths questionnaires can be used in 4 main ways within the coaching practice, i.e. by; (1) creating coaches' awareness of strengths; (2) carrying out strength assessment with clients; (3) using strength-based coaching to develop confidence; and (4) coaching clients to further develop their strengths to improve personal performance. Each one of these approaches will be discussed below in more detail.

\section{Creating Coaches' Awareness of Strengths}

There is a multiplicity of benefits associated with identifying strengths that can be helpful in various aspects of individuals' lives. For example, the benefits of strength awareness in the workplace was studied in a sample of 10,000 employees in New Zealand, and the results showed that those who were aware of their strengths were 9.5 times more likely to psychologically flourish than employees who had no such awareness (Hone et al., 2014). Coincidently, workplace strengths were also connected with employees' higher levels of vitality, concentration and experiencing harmonious passion (Dubreuil, Forest, \& Courcy, 2014) as well as engagement at work (Crabb, 2011). Therefore, in this context, coaches awareness of their own strengths may serve as a benefit to them when working with clients, by increasing coach confidence and deepening the coaches' self awareness, through self-reflection.

Whilst to date, there is no specific research about the impact of strength awareness on coaches' effectiveness at work, a study with psychotherapists showed that priming therapists' attention to their strengths five minutes before the therapy sessions showed improved therapeutic relationship and outcomes measured at session 20 (Fluckiger \& Grosse Holforth, 2008). Equally, when cognitive behavioural therapy was personalised to clients' strengths, as opposed to their deficits, the therapeutic process led yet again to better clients' outcomes (Cheavens, Strunk, Lazarus, \& Goldstein, 2012). Therefore, it is possible that the same applies to a coaching intervention, whereby focusing on clients' strengths prior to the coaching session, may prove beneficial to both coaches and their clients. However, more research needs to be carried out to confirm this. 


\section{Carrying Out Strength-Assessments with Clients}

Coaches may also use character strengths assessments as tools during a coaching intervention, either at an organisational client's request, as a strengths questionnaire, like the coaching, is part of the wider development programme, or because in discussion with the individual client, a strengths assessment has been agreed as part of the coaching assignment.

The coach may invite their client to complete one of the questionnaires as their homework before the session (Littman-Ovadia, Lazar-Butbul, \& Benjamin, 2014). Or the coach may use strength cards to facilitate a strengths based conversations with coaching clients (Jumpp, 2018; Markström, 2011; Smith \& Barros-Gomes, 2015). Strength cards may act as a more accessible and low cost way to encourage clients to reflect on their perceived strength. However, some clients may struggle to name their strengths (Hill, 2001), which would make such conversations more challenging than using an instrument that provides both terms and descriptions of these terms such as one of the strengths questionnaires discussed above.

When using any strength-assessments, Roche and Hefferon (2013) have argued that a structured coaching debriefing should form part of the process. In a qualitative study with 20 participants, they found that such a discussion lead to enhanced results, such as self-efficacy enhancement, stimulation of psychological development through self-awareness and insight, as well as strength development and use. Thus, if strengths are to be used in coaching, a structured approach is required for the most effective outcomes.

There are various models of strength discussions, that coaches may choose to apply, such as a simple identify and use approach (Biswas-Diener, 2010), or a threestep process of creating awareness, exploring strengths further and applying them accordingly (Niemiec, 2013). Regardless of what model is being used, the coach needs to consider the intricacies of strength assessment and evaluation (BiswasDiener, Kashdan, \& Minhas, 2011). We would argue, drawing from our practice, that strength-assessment is not about merely using strengths more, but using them in different social situations. Therefore, coaches need to help clients reflect upon how specific strengths can be used at work, at home and with friends, rather than simply encouraging clients to apply their strengths more frequently. Furthermore, we would suggest five factors that we have found useful when discussing strengths with clients: (1) strength tilt; (2) strength constellation; (3) strengths blindness; (4) strength sensitivity; and (5) social costs of strengths.

'Strength tilt' refers to an individual's interests and preferences, as well as ways in which strengths can be applied uniquely in each person, in order for them to live their lives in alignment with their values. Each strength profile identifies the 'Strength constellations', which are the interactions of strengths with each other. For example, an individual who frequently uses the strengths of fairness and bravery, would be more likely to stand up for someone who is unfairly treated than those who score highly in fairness but low in bravery. Therefore, such intricacies need to be considered in a coaching conversation. 'Strength blindness' refers to individuals not 
appreciating their strengths and viewing them as something common and ordinary, rather than something that needs to be celebrated and developed further. 'Strength sensitivity' may occur in clients who are being criticised around their strengths or when they discuss the negative aspects of their strengths. Finally, the 'Social cost of strengths' denotes the perception others have of individuals' strengths and the impact of it on how the client views their own strengths.

Each one of five factors need to be considered when debriefing clients on their strengths assessment. Recent developments in strength assessment also delves into the overuse and underuse of strengths as well as their optimal use to achieve desired results (Niemiec, 2018). Taking all into consideration, coach plays an important role in firstly guiding clients towards strength-assessments, but also in relation to helping clients make sense of the result of the assessment and the impact it has on their daily lives, as well as how individuals' strengths can be used more effectively in their lives.

\section{Strength-Based Coaching Practice}

The first attempt of using VIA character strengths in a one-to-one work with clients came from Seligman, Steen, Park and Peterson (2006) who made strengthsidentification and strength-use part of a positive psychotherapy intervention. This work was further developed into Strength-based Careers Counselling (SBCC) (Littman-Ovadia et al., 2014) when the researchers brought together strength-centred therapy (Wong, 2006) with a strength-based counselling model (Smith, 2006), and VIA character strengths assessment (Peterson \& Seligman, 2004). Their aim was to help career counsellors/coaches facilitate their clients employment. The study results showed that over $80 \%$ of strength-based intervention clients reported achieving their goals three months later, in comparison to $60 \%$ of traditionally coached clients. Furthermore, clients undertaking the SBCC evaluated their careers coach much more favourably than the control group clients. This study showed the positive impact that strength-based coaching may potentially have on both clients' outcomes, as well as their experience and satisfaction with the entire coaching process.

Strength-based coaching has also been shown to be effective when used with younger clients as well. In a pilot study with primary school children, researchers carried out group coaching sessions, during which they helped students identify their strengths and use them in an innovative way to strive for a personally meaningful goal, which resulted in their increased levels of engagement and hope (Madden, Green \& Grant, 2011). These results echo other findings with disadvantaged primary school children, for whom strength-based coaching prompted a process of improvement in social skills, anger management and school attitude (Dennison, Daniel, Gruber, Cavanaugh, \& Mayfield, 2018), as well as adolescents who have shown a decrease in depressive symptoms (Naify, 2009).

Similar studies, using strength-based models in a coaching practice have been used in business (Elston \& Boniwell, 2011; MacKie, 2014; Welch, Grossaint, Reid, \& Walker, 2014) and in coaching with private clients (McDowall \& Butterworth, 
2014). Therefore, whilst this is still a relatively new area of inquiry, the preliminary evidence is showing positive effects of using strength-based models. More research needs to be carried out in a coaching context in order to advance the theory and practice.

\section{Developing Specific Clients' Strengths to Improve Their Outcomes}

Over the last decade, a significant amount of research has focused on identifying specific strengths and their association with various outcomes. Writer such as Niemiec (2018) have encouraged practitioners to use this research with clients, encouraging them to develop their strengths in order to achieve their desired results. Research has shown perseverance is associated with work productivity (Littman-Ovadia \& Freidlin, 2019), whereas curiosity, zest, hope, gratitude and spirituality are associated with work satisfaction (Peterson, Stephens, Park, Lee, \& Seligman, 2010). Drawing on this research coaches may help clients achieve their goals but considering their personal strengths.

\section{Suggestions for Future Research}

Whilst all of the strength assessment organisations have developed tools for coaches allowing them to apply strengths in their work with clients (e.g. Brook, 2016; Strengthscope, 2018), there is limited research about the effectiveness of the questionnaires as a tool to enhance personal effectiveness.

Research is needed to explore the relationship between enhanced awareness, use of a specific strength and goal realisation. Work is also needed to examine in multiple context the application of strengths in work based tasks; does using a specific personal strength lead to performance gains?

\section{References}

Asplund, J., Agrawal, S., Hodges, T., Harter, J., Lopez, S. J. (2014). The Clifton Strenghtsfinder 2.0 technical report: Development and validation. Retrieved from: file:///Users/JolantaBurke/Downloads/Clifton\%20StrengthsFinder\%202.0\%20Technical\%20Report.pdf.

Biswas-Diener, R. (2010). Practicing positive psychology coaching: Assessment, activities, and strategies for success. Hoboken, NJ, US: Wiley. https://doi.org/10.1002/9781118269633.

Biswas-Diener, R., \& Dean, B. (2007). Positive psychology coaching: Putting the science of happiness to work for your clients. Hoboken, NJ, US: Wiley.

Biswas-Diener, R., Kashdan, T. B., \& Minhas, G. (2011). A dynamic approach topsychological strength development and intervention. Journal of PositivePsychology, 6, 106-118. 
BPS. (2017). Independent reviews of psychological tests. Retrieved from: https://www.bps.org.uk/ news-and-policy/independent-reviews-psychological-tests.

Brook, J. (2008, May). Accelerating performance with strengths coaching. Paper presented at Positive Psychology Coaching Day, London, UK.

Brook, J. (2016). A moment of weakness. Coaching at work, 11(2), 16-17.

Brook, J., \& Brewerton, P. (2006). Strengthscope technical manual. London: Strengths Partnership.

Burke, J. (2018). Conceptual framework for a positive psychology coaching practice. Coaching Psychologist, 14(1), 16-25.

CAPP. (2010). Technical manual and statistical properties for Realise2. Coventry, UK: CAPP.

Cheavens, J. S., Strunk, D. R., Lazarus, S. A., \& Goldstein, L. A. (2012). The compensation and capitalization models: A test of two approaches to individualizing the treatment of depression. Behaviour Research and Therapy, 50(11), 699-706. https://doi.org/10.1016/j.brat.2012.08.002.

Clifton, D. O., \& Anderson, E. C. (2001-02). StrengthsQuest. Washington: The Gallup Organisation.

Crabb, S. (2011). The use of coaching principles to foster employee engagement. The Coaching Psychologist, 7(1), 27-34.

Dennison, S. T., Daniel, S. S., Gruber, K. J., Cavanaugh, A. M., \& Mayfield, A. (2018). A leadership training group for at risk fifth \& seventh graders: Results from a brief strength-based group program. Social Work with Groups, 41(3), 181-197. https://doi.org/10.1080/01609513. 2017.1330170.

Drake, R. M. (1935). What is musical talent? Tempo, 27-29.

Dubreuil, P., Forest, J., \& Courcy, F. (2014). From strengths use to work performance: The role of harmonious passion, subjective vitality, and concentration. Journal Of Positive Psychology, 9(4), 335-349. https://doi.org/10.1080/17439760.2014.898318.

Duckworth, A. L. (2016). Grit: The power of passion and perseverance. London: Vermillion.

Duckworth, A. L., Eichstaedt, J. C., \& Ungar, L. H. (2015). The mechanics of human achievement. Social and Personality Psychology Compass, 9(7), 359-369. https://doi.org/10.1111/spc3.12178.

Dweck, C. (2009). Mindset: Changing the way you think to fulfill your potential. New York: Random House.

Elston, F., \& Boniwell, I. (2011). A grounded theory study of the value derived by women in financial services through a coaching intervention to help them identify their strengths and practise using them in the workplace. International Coaching Psychology Review, 6(1), 16-32.

Fluckiger, C., \& Grosse Holtforth, M. (2008). Focusing the therapist's attention on the patient's strengths: A preliminary study to foster a mechanism of change in outpatient psychotherapy. Journal of Clinical Psychology, 64, 876-890.

Freidlin, P., Littman-Ovadia, H., \& Niemiec, R. M. (2017). Positive psychopathology: Social anxiety via character strengths underuse and overuse. Personality and Individual Differences, 108, 50-54. https://doi.org/10.1016/j.paid.2016.12.003.

Freire, T. (2013). Positive psychological Approaches. In J. Passmore, D. Peterson \& T. Freire (Eds.), The Wiley Blackwell handbook of the psychology of coaching and mentoring (pp. 426-442). Chichester: Wiley.

Furnham, A. (2015). Backstabers and bullies: How to cope with the dark side of people at work. London: Bloomsbury.

Gallup. (2008). Strength-based development consulting services. Retrieved from: https://www. gallup.com/services/176315/gallup-strengths-based-development-consulting-services.aspx.

Gallup. (2018). Understand how your talents work with others. Retrieved from: https://www. gallupstrengthscenter.com/home/en-us/cliftonstrengths-themes-domains.

Goldstein, H., Pulakos, E., Passmore, J., \& Semedo, C. (2017). The Wiley Blackwell handbook of the psychology of recruitment, selection and employee retention. Chichester: Wiley.

Hill, J. (2001). How well do we know our strengths? Paper presented at the British Psychological Society Centenary Conference, Glasgow, April.

Hogan, R. (2007). Personality and the fate of organisations. New York: Psychology Press. 
Hone, L. C., Jarden, A., Schofield, G. M., \& Duncan, S. (2014). Measuring flourishing: The impact of operational definitions on the prevalence of high levels of wellbeing. International Journal of Wellbeing, 4(1), 62-90. https://doi.org/10.5502/ijw.v4i1.4.

Jumpp. (2018). Character strength cards. Dublin: Jumpp.

Kashdan, T. B., Blalock, D. V., Young, K. C., Machell, K. A., Monfort, S. S., McKnight, P. E., et al. (2018). Personality strengths in romantic relationships: Measuring perceptions of benefits and costs and their impact on personal and relational well-being. Psychological Assessment, 30, 241-258.

Kaufman, C., Silbermann, J., \& Sharpley, D. (2012). Coaching for strength using VIA. In J. Passmore (Ed.), Psychometrics in Coaching: Using psychological and psychometric tools for development. London: Kogan Page.

Littman-Ovadia, H., \& Freidlin, P. (2019). Positive psychopathology and positive functioning: OCD, flourishing and satisfaction with life through the lens of character strength underuse, overuse and optimal use. Applied Research in Quality of Life, 1-21. https://doi.org/10.1007/s11482-018-97015

Littman-Ovadia, H., Lazar-Butbul, V., \& Benjamin, B. A. (2014). Strengths-based career counseling: Overview and initial evaluation. Journal of Career Assessment, 22(3), 403-419. https://doi. org/10.1177/1069072713498483.

Lombardo, M., \& Eichinger, R. (1999). Preventing derailment. Greensboro: Centre for Creative Leadership.

MacKie, D. (2014). The effectiveness of strength-based executive coaching in enhancing full range leadership development: A controlled study. Consulting Psychology Journal: Practice and Research, 66(2), 118-137. https://doi.org/10.1037/cpb0000005.

MacKie, D. (2015). Coaching for strength based leadership. In J. Passmore (Ed.), Leadership coaching: Working with leaders to develop elite performance. London: Kogan Page.

Madden, W., Green, S., \& Grant, A. M. (2011). a pilot study evaluating strengths-based coaching for primary school students: Enhancing engagement and hope. International Coaching Psychology Review, 6, 71-83.

Markström, A. (2011). To involve parents in the assessment of the child in parent-teacher conferences: A case study. Early Childhood Education Journal, 38(6), 465-474. https://doi.org/10. 1007/s10643-010-0436-7.

McDowall, A., \& Butterworth, L. (2014). How does a brief strengths-based group coaching intervention work? Coaching: An International Journal of Theory, Research and Practice, 7(2), 152-163. https://doi.org/10.1080/17521882.2014.953560.

McGrath, R. E. (2014). Scale- and item-level factor analyses of the VIA Inventory of Strengths. Assessment, 21(1), 4-14. https://doi.org/10.1177/1073191112450612.

McGrath, R. E. (2017a). Technical report: The VIA assessment suit for adults: Development and validation. Cincinnati, OH: VIA Institute on Character.

McGrath, R. E. (2017b). New assessments available on the VIA site. Cincinnati, OH: VIA Institute on Character.

McLean, B. (2004). The smartest guys in the room: The amazing rise and scandalous fall of enron. New York: Penguin.

Michaels, E., Handfield-Jones, H., \& Axelrod, B. (2001). The war for talent. Harvard, MA: Harvard Business Press.

Mongrain, M., \& Anselmo-Matthews, T. (2012). Do positive psychology exercises work? A replication of Seligman. Journal of Clinical Psychology, 68(4), 382-389.

Naify, A. M. (2009). The effectiveness of a brief strength-based intervention on depression in at-risk adolescent girls. Dissertation Abstracts International, 70, 3791.

Niemiec, R. M. (2013). VIA character strengths: Research and practice (the first 10 years). In H. H. Knoop, A. Delle Fave, H. H. Knoop, \& A. Delle Fave (Eds.), Well-being and cultures: Perspectives from positive psychology (pp. 11-29). New York, NY, US: Springer Science + Business Media. https://doi.org/10.1007/978-94-007-4611-4_2. 
Niemiec, R. M. (2018). Character strengths interventions: A field guide for practitioners. Toronto, CA: Hogrefe.

Passmore, J., \& Oades, L. G. (2014a). Positive psychology coaching techniques: Active constructive responding. The Coaching Psychologist, 10(2), 71-73.

Passmore, J., \& Oades, L. G. (2014b). Positive psychology coaching-A model for coaching practice. Coaching Psychologist, 10(2), 68-70.

Passmore, J., \& Oades, L. G. (2015a). Positive psychology coaching techniques: Random acts of kindness, consistent acts of kindness \& empathy. The Coaching Psychologist, 11(2), 90-92.

Passmore, J., \& Oades, L. G. (2015b). Positive psychology coaching techniques: Positive case conceptualisation. The Coaching Psychologist, 11(1), 43-45.

Passmore, J., \& Oades, L. G. (2016). Positive psychology coaching techniques: Gratitude. The Coaching Psychologist, 12(1), 34-35.

Peterson, C., Park, N., \& Seligman, M. E. P. (2005). Assessment of character strengths. In G. P. Koocher, J. C. Norcross, \& S. S. Hill III (Eds.), Psychologists' desk reference (2nd ed., pp. 93-98). New York: Oxford University Press.

Peterson, T. D., \& Peterson, E. W. (2008). Stemming the tide of law student depression: What law schools need to learn from the science of positive psychology. Yale Journal of Health Policy, Law, and Ethics, 9(2). Available at: http://ssrn.com/abstract=1277303.

Peterson, C., \& Seligman, M. E. P. (2004). Character strengths and virtues: A handbook and classification. Washington, DC: American Psychological Association.

Peterson, C., Stephens, J. P., Park, N., Lee, F., \& Seligman, M. E. P. (2010). Strengths of character and work. In P. A. Linley, S. Harrington, \& N. Garcea (Eds.), Oxford library of psychology. Oxford handbook of positive psychology and work (pp. 221-231). New York, NY, US: Oxford University Press.

Proyer, R. T., Wellenzohn, S., Gander, F., \& Ruch, W. (2014). Toward a better understanding of what makes positive psychology interventions work: Predicting happiness and depression from the person $\times$ intervention fit in a follow-up after 3.5 years. Applied Psychology: Health and Well-Being. https://doi.org/10.1111/aphw.12039.

Roche, B., \& Hefferon, K. (2013). 'The assessment needs to go hand-in-hand with the debriefing': The importance of a structured coaching debriefing in understanding and applying a positive psychology strengths assessment. International Coaching Psychology Review, 8(1), 20-34.

Rust, T., Diessner, R., \& Reade, L. (2009). Strengths only or strengths and relative weaknesses? A preliminary study. Journal of Psychology, 143(5), 465-476.

Seligman, M. E. P., Steen, T., Park, N., \& Peterson, C. (2005). Positive psychology progress: Empirical validation of interventions. American Psychologist, 60, 410-421.

Smith, E. J. (2006). The strength-based counseling model. The Counseling Psychologist, 34, 13-79.

Smith, E. N., \& Barros-Gomes, P. (2015). Soliciting strengths systemically: The use of character strengths in couple and family therapy. Journal of Family Psychotherapy, 26(1), 42-46. https:// doi.org/10.1080/08975353.2015.100274.

Strengthscope. (2018). STRONG business coaching guidelines. London: Strengths Partnership Ltd.

Subarsky, Z. (1948). What is science talent? (pp. 66377-66382). New York: Scientific Monthly.

Tansley, C. (2011). What do we mean by the term "talent" in talent management? Industrial and Commercial Training, 43(5), 266-274. https://doi.org/10.1108/00197851111145853.

VIA-IS. (2018). Values in action inventory of strengths. Retrieved from http://www.viacharacter. org/www/.

Weick, A., \& Saleebey, D. (1995). Supporting family strengths: Orienting policy and practice toward the 21st century. Families in Society: Journal of Contemporary Social Services, 76(3), 141-149.

Welch, D., Grossaint, K., Reid, K., \& Walker, C. (2014). Strengths-based leadership development: Insights from expert coaches. Consulting Psychology Journal: Practice and Research, 66(1), 20-37. https://doi.org/10.1037/cpb0000002.

Wong, Y. J. (2006). Strengths-centered therapy: A social constructionist, virtues-based psychotherapy. Psychotherapy: Theory, Research, Practice, and Training, 43, 133-146. 
Jolanta Burke, Ph.D. is a senior lecturer and co-leader of the Masters in Applied Positive Psychology and Coaching Psychology at the University of East London. She has been a practicing coach for almost 15 years, working mainly in a business environment with leaders and sales professionals. She has published articles in academic journals, popular magazines, newspapers and spoke at events across 4 continents. Dr Burke is an author of "Happiness after 30: The paradox of aging" and a soon-to-be-published book on applying positive psychology to a coaching practice. For more information, please go to www.jolantaburke.com.

Jonathan Passmore is director of Henley centre for coaching, Henley Business School, University of Reading and professor of psychology at the University of Evora. He has written and edited over thirty books and 100 scientific papers and book chapters, including the eight volume series on Industrial Psychology for Wiley-Blackwell. His work has been internationally recognised with multiple awards including the Outstanding Contribution to Coaching Award from the British Psychological Society in 2017. 